IZA DP No. 9412

The Welfare Effects of Globalization

with Labor Market Regulation

Tapio Palokangas

October 2015 


\title{
The Welfare Effects of Globalization with Labor Market Regulation
}

\author{
Tapio Palokangas \\ HECER, University of Helsinki \\ and IZA
}

\section{Discussion Paper No. 9412 \\ October 2015}

\author{
IZA \\ P.O. Box 7240 \\ 53072 Bonn \\ Germany \\ Phone: +49-228-3894-0 \\ Fax: +49-228-3894-180 \\ E-mail: iza@iza.org
}

\begin{abstract}
Any opinions expressed here are those of the author(s) and not those of IZA. Research published in this series may include views on policy, but the institute itself takes no institutional policy positions. The IZA research network is committed to the IZA Guiding Principles of Research Integrity.

The Institute for the Study of Labor (IZA) in Bonn is a local and virtual international research center and a place of communication between science, politics and business. IZA is an independent nonprofit organization supported by Deutsche Post Foundation. The center is associated with the University of Bonn and offers a stimulating research environment through its international network, workshops and conferences, data service, project support, research visits and doctoral program. IZA engages in (i) original and internationally competitive research in all fields of labor economics, (ii) development of policy concepts, and (iii) dissemination of research results and concepts to the interested public.
\end{abstract}

IZA Discussion Papers often represent preliminary work and are circulated to encourage discussion. Citation of such a paper should account for its provisional character. A revised version may be available directly from the author. 
IZA Discussion Paper No. 9412

October 2015

\section{ABSTRACT \\ The Welfare Effects of Globalization with Labor Market Regulation}

I examine how globalization affects wages and welfare in a general equilibrium model of international trade with partly oligopolistic markets. Globalization is modeled as reducing trade costs or opening up shielded sectors to trade. There is a national or international common agency that determines minimum wages for the oligopolists, either directly or through supporting labor unions. The lobbies of employers and labor unions influence that agency, relating their prospective political contributions to the latter's decisions. Both a shift from national to international regulation and a decrease in trade costs promote aggregate welfare, but decrease open-sector relative wages.

JEL Classification: $\quad$ C72, F16, J51

Keywords: globalization, international trade, common agency, regulation, labor unions

Corresponding author:

Tapio Palokangas

University of Helsinki

P.O. Box 17 (Arkadiankatu 7)

FIN-00014 Helsinki

Finland

E-mail: Tapio.Palokangas@helsinki.fi 


\section{Introduction}

In modern economies, the wages are in general determined by a complex political process in which the employers and labor unions on the one hand, and the governments and authorities regulating the labor market on the other hand play a crucial role. Given this process, I explore the effects of international economic integration on wages and aggregate welfare.

The traditional way of considering globalization analyzes the impact of trade cost reductions or opening up to trade on bargained wages through the elasticity of labor demand. Huizinga (1993) and Driffill and Vander Ploeg (1995) claim that the integration of markets increase the elasticity of labor demand, decreasing bargained wages. Naylor $(1998,1999)$ indicates the opposite. Bastos and Kreickemeier (2009) as well as Kreickemeier and Meland (2013) combine Neary's (2009) general oligopolistic equilibrium model with unionized labor markets, repeating Naylor's conclusion. All these articles, however, assume that relative union bargaining power is wholly exogenous (e.g. monopoly unions). In this article, I assume that labor market regulation is a political process that determines union power endogenously.

There is plenty of anecdotal evidence on changing union power. Unionization has declined in most OECD countries since the 1980s (Nickell et al. 2005, pp. 6-7). In particular, in the years 1975-2000, labor markets have been rapidly deregulated in the US and UK (Acemoglu et al. 2001). Globalization has undermined union bargaining power (cf. Abraham et al. 2009, Dumont at al. 2006, 2012, Boulhol et al. 2011). Protection of regular employment contracts was diminished when globalization was proceeding rapidly (Potrafke 2010). Given this evidence, it is instructive to consider relative union bargaining power as endogenous in a model of international trade.

The political economy can be modeled either by majority voting (cf. Saint-Paul 2002a, 2002b), all-pay auctioning, in which the lobbyist making the greater effort wins with certainty (cf. Johal and Ulph 2002), or menu actioning, in which the lobbyists announce their bids contingent on the policy maker's actions (cf. Dixit et al 1997). With all-pay auctioning, lobbying expenditures are incurred by all the lobbyists before the policy maker takes an action. This is the case e.g. when interest groups spend money to increase the probability of getting their favorite type of government elected. With 
menu auctioning, it is not possible for a lobbyist to spend money and effort on lobbying without getting what he lobbied for. Because menu auctioning fits best for the case where employers and labor unions obtain marginal improvements for their position by lobbying, I take it as a starting point.

Using the political economy model of menu auctioning, Palokangas (2003) shows that distorting taxation can cause labor market regulation: if employers and workers bargain over wages and lobby the government over taxation and labor market regulation, and if it is much easier to tax wages than profits, then the government has incentives to protect union power. Palokangas (2014) shows that an increase in the number of common agencies tend to decrease union power in an economy with R\&D-based growth.

The main idea of this article is the following. While monopoly unions set wages to maximize the workers' rents, the political economy of labor market regulation results in wages that maximize the workers' and employers' total rents. Consequently, globalization tends to decrease open-sector relative wages and aggregate welfare in the case of monopoly unions (cf. Kreickemeier and Meland 2013), but to increase those in the case of labor market regulation. I organize the remainder of this article as follows. The structure of the economy is presented in section 2. The specific models of the households, firms and labor markets are constructed in 3 and 4. A common agency game where employers and labor unions lobby common agencies is presented in 5. The political equilibrium of that game is established in 6. Finally, the general equilibrium and welfare effects of globalization are considered in 7 .

\section{The economy}

There are two identical countries, home and foreign, that possess a fixed amount $L$ of labor and a "continuum" of sectors $i \in[0,1]$. Each sector $i$ produces one unit of a separate good $i$ from one unit of labor. As in Brander and Krugman (1983), there are segmented markets and a specific unit tariff $\tau>0$ for traded goods. Because this tariff characterizes implicit trade barriers, following Kreickemeier and Meland (2013), I assume that tariff revenues from foreign firms accrue to home employers only, for simplicity.

The sectors $i \in[0,1]$ can be divided into three distinct sets: competitive sectors $M$, open (and oligopolistic) sectors $P$ producing traded goods, and 
shielded (and oligopolistic) sectors $S$ producing non-traded goods. ${ }^{1}$ The masses of open, shielded and competitive sectors are constants $(\alpha, \beta, \gamma)$ :

$$
\int_{i \in M} d i=\gamma, \quad \int_{i \in P} d i=\alpha, \quad \int_{i \in S} d i=\beta=1-\gamma-\alpha
$$

All oligopolistic sectors $i \in P \cup S=[0,1] \backslash M$ contain the same given number $n$ of oligopolistic firms. The tariff $\tau>0$ prevents any trade of the competitive goods $i \in M$ between the two identical countries. Opening up shielded sectors to trade is equivalent to increasing $\alpha$ with an equal decrease in $\beta$. Denoting the demand for labor in sector by $l(i)$ and the variables associated with the foreign country by superscript $\left({ }^{*}\right)$, the equilibrium conditions of the labor markets can be written as follows:

$$
L=\int_{0}^{1} l(i) d i, \quad L=L^{*}=\int_{0}^{1} l^{*}(i) d i
$$

I assume that there is a common agency (e.g. a government or some other authority) that determines the (national or international) minimum wages for the oligopolistic sectors $i \in P \cup S$. The unions and employers influence this by their political contributions. In Appendix A, I extend the results for the case where the common agency do not set the minimum wages directly, but supports labor unions that bargain with oligopolists over the wages.

The political equilibrium is established by the common agency model (c.f. Bernheim and Whinston 1986 and Dixit et al. 1997). The agents are households, firms, union and employer lobbies, and common agencies. Their decisions form an extensive form game as follows:

(i) The employer and union lobbies influence the common agency, relating their prospective political contributions to the latter's decisions.

\footnotetext{
${ }^{1}$ This structure follows Kreickemeier and Meland (2013), but with the following exception. The competitive sectors in the model of this article provide a reservation wage for labor unions. KM introduce non-unionized (but oligopolistic) sectors into their model for the same purpose, but assuming exogenous union power. Because union power is determined by political process in this article, it would be implausible to assume that union power is allowed in some, but not in the other sectors. If there is no union in a sector, then the best explanation is that there are no rents to be bargained over.
} 
(ii) The common agency sets wages for the oligopolistic sectors $i \in P \cup S$, and collects political contributions.

(iii) The competitive wage $w_{m}$ adjusts to balance the labor market.

(iv) The firms employ labor.

(v) The households decide on consumption.

This game is solved by backward induction: stage (v) is examined in section 3 , stages (iv) and (iii) in 4, stage (ii) in 5 and stage (i) in 6 . At each stage, I consider the behavior of home agents, but because the countries are identical, the foreign agents behave in the same manner.

\section{The households}

Following Neary (2009), I assume that the representative home household derives utility $U$ from the consumption $c(i)$ of the goods $i \in[0,1]$ as follows:

$$
u \doteq \int_{0}^{1}\left[a c(i)-\frac{b}{2} c(i)^{2}\right] d i
$$

where $a$ and $b$ are positive constants. Denoting income by $I$ and the price for good $i$ by $p(i)$, the home budget constraint can be written as follows:

$$
I=\int_{0}^{1} p(i) c(i) d i
$$

The maximization of utility (3) by consumption $c(i)$ subject to the budget constraint (4) leads to the inverse demand functions $p(i)=[a-b c(i)] / \lambda$, where $\lambda$ is the marginal utility of income. Following Neary (2009), I normalize $\lambda$ at one. The inverse demand functions take then the form

$$
p(i)=a-b c(i)
$$

The index of the prices (5) is given by

$$
\mu_{1} \doteq \int_{0}^{1} p(i) d i=a-b \int_{0}^{1} c(i) d i
$$


Because one unit of each good $i$ is produced from one unit of labor, consumption $\int_{0}^{1}\left[c(i)+c^{*}(i)\right] d i$ must be equal to employment $\int_{0}^{1}\left[l(i)+l^{*}(i)\right] d i=2 L$ in the two countries taken together [cf. (2)]. Because the countries are identical, then, $c^{*}(i)=c(i)$ and $\int_{0}^{1} c(i) d i=L$ hold true in equilibrium, and it follows from (6) that the price index $\mu_{1}=a-b L$ is constant in equilibrium.

Plugging the direct demands $c(i)=[a-p(i)] / b[\mathrm{cf}$. (5)] into the budget constraint (4) and the utility function (3) yields the uncentred variance of prices, $\mu_{2}$, and indirect utility as follows:

$$
\mu_{2} \doteq \int_{0}^{1} p(i)^{2} d i=a \mu_{1}-b I, \quad u=\frac{a^{2}}{2 b}-\frac{\mu_{2}}{2 b}=\frac{a^{2}}{2 b}-\frac{a \mu_{1}}{2 b}+\frac{I}{2}
$$

Because utility $u$ depends linearly on $I$ only, income $I$ can be used as a proxy for utility $u$ at all levels of aggregation.

\section{Production}

I assume that the home agency can set different wages $w_{p}$ and $w_{s}$ for the open and shielded sectors, respectively. In Appendix A, the results are generalized for the case of collective bargaining with labor unions.

\subsection{Shielded sectors $i \in S$}

Consumption $c(i)$ equals employment $l(i)$ in shielded sectors:

$$
c(i)=l(i)=\sum_{j=1}^{n} l_{j}(i) \text { for } i \in S,
$$

where $l_{j}(i)$ is the labor input of firm $j$. Noting the inverse demand function (5) and technology (7), the profit of home firm $j$ can be written as follows:

$$
\pi_{j}(i) \doteq\left[p(i)-w_{s}\right] l_{j}(i)=\left[a-b \sum_{\kappa=1}^{n} l_{\kappa}(i)-w_{s}\right] l_{j}(i) \text { for } i \in S
$$

Home firm $j$ maximizes profit (8) by its input $l_{j}(i)$, given the wage $w(i)$ and the inputs of the other firms, $\sum_{\kappa \neq j}^{n} l_{\kappa}(i)$. Cournot competition between the 
$n$ identical firms yields

$$
c(i)=c_{s}=l(i)=l_{s}=n l_{j}(i)=\frac{n\left(a-w_{s}\right)}{(n+1) b} \text { and } p(i)=p_{s}=\frac{a+n w_{s}}{n+1}
$$

for $i \in S$.

\subsection{Open sectors $i \in P$}

The employment of home firm $j$ equals its output for the home markets, $x_{j}(i)$, and that for the foreign markets, $y_{j}(i)$ :

$$
l_{j}(i)=x_{j}(i)+y_{j}(i) \text { for } i \in P \text {. }
$$

The consumption of good $i \in P, c(i)$, equals the home production of that good, $x_{j}(i)$, plus imports from abroad, $y_{j}^{*}(i)$ :

$$
c(i)=\sum_{\kappa=1}^{n}\left[x_{\kappa}(i)+y_{\kappa}^{*}(i)\right] \text { for } i \in P .
$$

Noting the inverse demand function (5) and technology (10) and (11), the profit of home firm $j$ can be written as follows:

$$
\begin{aligned}
\pi_{j}(i) \doteq\left[p(i)-w_{p}\right] x_{j}(i)+\left[p^{*}(i)-w_{p}-\tau\right] y_{j}(i) \\
=\left\{a-b \sum_{\kappa=1}^{n}\left[x_{\kappa}(i)+y_{\kappa}^{*}(i)\right]-w_{p}\right\} x_{j}(i) \\
\quad+\left\{a-b \sum_{\kappa=1}^{n}\left[x_{\kappa}^{*}(i)+y_{\kappa}(i)\right]-w_{p}-\tau\right\} y_{j}(i) \text { for } i \in P .
\end{aligned}
$$

Home firm $j$ in sector $i \in P$ maximizes its profit (12) by its inputs $x_{j}(i)$ and $y_{j}(i)$, given the wage $w_{p}$ and the inputs of the other firms, $x_{\kappa}(i)$ and $y_{\kappa}(i)$ for $\kappa \neq j$ and $x_{\kappa}^{*}(i)$ and $y_{\kappa}^{*}(i)$ for $j \in[0,1]$. Foreign firm $j$ in that sector behaves accordingly, given the others' inputs and the foreign open-sector 
wage $w_{p}^{*}{ }^{2}$ Kreickemeier and Meland (2013) prove that if the tariff $\tau$ is low enough for having trade in the open sectors, there is Cournot competition between $n$ identical home and $n$ identical foreign firms, where the latter have higher effective (trade-cost inclusive) marginal cost. This competition yields

$$
\begin{aligned}
& y(i)=y=n y_{j}(i)=n \frac{a-(n+1)\left(w_{p}+\tau\right)+n w_{p}^{*}}{(2 n+1) b} \text { for } i \in P, \\
& y^{*}(i)=y^{*}=n y_{j}^{*}(i)=n \frac{a-(n+1)\left(w_{p}^{*}+\tau\right)+n w_{p}}{(2 n+1) b} \text { for } i \in P, \\
& y^{*}-y=\frac{n}{b}\left(w_{p}-w_{p}^{*}\right), \\
& l(i)=l_{p}=n\left[x_{j}(i)+y_{j}(i)\right]=n \frac{2\left[a+n w_{p}^{*}-(n+1) w_{p}\right]-\tau}{(2 n+1) b}, \\
& c(i)=c^{*}(i)=c_{p}=n\left[x_{j}(i)+y_{j}^{*}(i)\right]=n \frac{2 a-w_{p}-w_{p}^{*}-\tau}{(2 n+1) b} \text { and } \\
& p^{*}(i)=p(i)=p_{p}=\frac{1}{2 n+1}\left\{(n+1) a+n\left(w_{p}+w_{p}^{*}+\tau\right)\right\} \text { for } i \in P .
\end{aligned}
$$

\subsection{Competitive sectors $i \in M$}

In the competitive sectors, the prices equal the competitive wage $w_{m}$, and, because the tariff $\tau>0$ prevents trade between the identical countries, home consumption $c(i)$ equals home output $l(i)$ [cf. (5)]:

$$
p(i)=w_{m} \text { and } l_{m}=l(i)=c(i)=\frac{a-p(i)}{b}=\frac{a-w_{m}}{b} \text { for } i \in M .
$$

Given (1), (14) and (15), the full-employment constraint (2) takes the form

$$
L=\int_{i \in M} l(i) d i+\int_{i \in S} l(i) d i+\int_{i \in P} l(i) d i=\alpha l_{p}+\beta l_{s}+\gamma l_{m}
$$

\footnotetext{
${ }^{2}$ This is equivalent to the reciprocal dumping model of Brander and Krugman (1983). Exports occur if and only if the tariff $\tau$ is below a critical level that is implicitly given by the condition that effective marginal cost of serving the export market, $w_{p}+\tau$, equals the price in this market in the absence of trade, $\left.\left(a+n w_{p}\right)\right] /(n+1)$, which is also the marginal revenue of the exporting firm for the first unit sold abroad.
} 
Solving for $w_{m}$ from this and noting (9) and (14), one obtains the competitive wage that clears the labor market:

$$
\begin{aligned}
w_{m} & =a-b l_{m}=a+\frac{b}{\gamma}\left(\alpha l_{p}+\beta l_{s}-L\right) \\
& =a-\frac{b}{\gamma} L+\frac{\alpha}{\gamma} n \frac{2\left[a+n w_{p}^{*}-(n+1) w_{p}\right]-\tau}{2 n+1}+\frac{\beta}{\gamma} n \frac{a-w_{s}}{n+1} .
\end{aligned}
$$

\section{Lobbies and the common agency}

Noting (8), (12) and (14), one can obtain the employers' sectorial rents

$$
\pi(i)= \begin{cases}\sum_{j=1}^{n} \pi_{j}(i)=\left[p(i)-w_{p}\right] l(i)-\tau y(i) & \text { for } i \in P \\ \sum_{j=1}^{n} \pi_{j}(i)=\left[p(i)-w_{s}\right] l(i) & \text { for } i \in S\end{cases}
$$

and the workers' sectorial rents over and above the competitive wage $w_{m}$,

$$
v(i)=\left[w(i)-w_{m}\right] l(i) \text { for } i \in P \cup S
$$

The tariff revenues from foreign firms, $\tau \int_{i \in P} y^{*}(i) d i$, accrue the home employers only. Given this, (1), (4), (13), (14), (15), (17), (18) and (19), total income $I$ and the employers' and workers' total rents, $\Pi$ and $W$, become

$$
\begin{aligned}
& I=p_{p} c_{p}+p_{s} c_{s}+p_{m} c_{m} \\
& \begin{aligned}
\Pi\left(w_{s}, w_{p}, w_{p}^{*}, \tau, \alpha\right) & \doteq \int_{i \in P \cup S} \pi(i) d i+\tau \int_{i \in P} y^{*}(i) d i \\
& =\alpha\left(p_{p}-w_{p}\right) l_{p}+\beta\left(p_{s}-w_{s}\right) l_{s}+\alpha \tau\left(y^{*}-y\right) \\
& =\alpha\left(p_{p}-w_{p}\right) l_{p}+\beta\left(p_{s}-w_{s}\right) l_{s}+\alpha \frac{n}{b} \tau\left(w_{p}-w_{p}^{*}\right),
\end{aligned} \\
& W\left(w_{s}, w_{p}, w_{p}^{*}, \tau, \alpha\right) \\
& \doteq \int_{0}^{1} v(i) d i=\alpha\left(w_{p}-w_{m}\right) l_{p}+\beta\left(w_{s}-w_{m}\right) l_{s} .
\end{aligned}
$$


I assume that all unions belong to the same lobby, for convenience. ${ }^{3}$ The union lobby attempts to maximize the workers' rents $W$ minus its political contributions $R_{W}, I_{W} \doteq W-R_{W}$, while the employer lobby attempts to maximize the employers' rents $\Pi$ minus its political contributions $R_{\Pi}$ to the common agency, $I_{\Pi} \doteq \Pi-R_{\Pi}$. Following Dixit et al. (1997), I assume that the common agency's utility $G$ is an increasing function of the utilities of both lobbies, $I_{W}$ and $I_{\Pi}$, and the total contributions $R_{P}+R_{W}$ it receive:

$$
\begin{aligned}
& I_{W}\left(w_{s}, w_{p}, w_{p}^{*}, \tau, \alpha, R_{W}\right) \doteq W-R_{W}, \quad I_{\Pi}\left(w_{s}, w_{p}, w_{p}^{*}, \tau, \alpha, R_{\Pi}\right) \doteq \Pi-R_{\Pi} \\
& G\left(I_{W}, I_{\Pi}, R_{W}+R_{\Pi}\right), \quad \frac{\partial G}{\partial I_{W}}>0, \quad \frac{\partial G}{\partial I_{\Pi}}>0, \quad \frac{\partial G}{\partial\left(R_{W}+R_{\Pi}\right)}>0
\end{aligned}
$$

Following Dixit (1986), I assume that the home agency and the home lobbies anticipate their foreign counterparts to follow their choice of the opensector wage $w_{p}$ according to the conjectural variation relation

$$
\frac{d w_{p}^{*}}{d w_{p}}=\varphi \in\{0,1\}
$$

This a way of incorporating national labor market regulation $(\varphi=0)$, in which the home and foreign agencies behave in Cournot manner, taking each other's wages as given, and international labor market regulation $(\varphi=1)$ in which the countries have the same common agency, into the same model.

\section{Political Equilibrium}

According to Dixit et al. (1997), a subgame perfect Nash equilibrium for the game between the employer lobby, the union lobby and the common agency is a set of contribution schedules $R_{\Pi}\left(w_{s}, w_{p}, w_{p}^{*}\right)$ and $R_{W}\left(w_{s}, w_{p}, w_{p}^{*}\right)$ and policy $\left(w_{s}, w_{p}\right)$ that satisfy the following conditions $(i)-(i v)$ :

\footnotetext{
${ }^{3}$ Because the workers' and employers' rents, (22) and (18), are additive over the open and shielded sectors, the results would be the same even if the unions and employers had separate lobbies in the open and shielded sectors, provided that tariff revenues from foreign firms, $\tau \int_{i \in P} y^{*}(i) d i$, accrue the home open-sector employers only.
} 
(i) The contributions of the lobbies, $R_{\Pi}$ and $R_{W}$, are non-negative but no more than the contributor's income.

(ii) With a feasible strategy $R_{\Pi}\left(w_{s}, w_{p}, w_{p}^{*}\right)\left(R_{W}\left(w_{s}, w_{p}, w_{p}^{*}\right)\right)$, the employer (labor) lobby maximizes its utility $I_{\Pi}\left(I_{W}\right)$ by wages $\left(w_{s}, w_{p}\right)$ s.t. $(24)$ :

$$
\begin{aligned}
& \left(w_{s}, w_{p}\right)=\arg \max _{\left(w_{s}, w_{p}\right) \text { s.t. }(24)} I_{\Pi}\left(w_{s}, w_{p}, w_{p}^{*}, \tau, \alpha, R_{\Pi}\right), \\
& \left(w_{s}, w_{p}\right)=\arg \max _{\left(w_{s}, w_{p}\right) \text { s.t. }(24)} I_{W}\left(w_{s}, w_{p}, w_{p}^{*}, \tau, \alpha, R_{W}\right) .
\end{aligned}
$$

(iii) Wages $\left(w_{s}, w_{p}\right)$ maximize the agency's welfare (23) s.t. (24) [cf. (25)]:

$$
\begin{aligned}
\left(w_{s}, w_{p}\right) & =\arg \max _{\substack{\left(w_{s}, w_{p}\right) \\
\text { s.t. }(24)}} G\left(\max _{\substack{\left(w_{s}, w_{p}\right) \\
\text { s.t. }(24)}} I_{\Pi}, \max _{\substack{\left(w_{s}, w_{p}\right) \\
\text { s.t. }(24)}} I_{W}, R_{\Pi}+R_{W}\right) \\
& =\arg \max _{\left(w_{s}, w_{p}\right) \text { s.t. }(24)}\left[R_{\Pi}\left(w_{s}, w_{p}, w_{p}^{*}\right)+R_{W}\left(w_{s}, w_{p}, w_{p}^{*}\right)\right] .
\end{aligned}
$$

(iv) The employer (labor) lobby provides the common agency at least with the level of utility than in the case where it offers nothing $R_{W}=0$ $\left(R_{\Pi}=0\right)$, and where the common agency responds optimally given the other lobby's contribution function $R_{\Pi}\left(w_{s}, w_{p}, w_{p}^{*}\right)\left(R_{W}\left(w_{s}, w_{p}, w_{p}^{*}\right)\right)$.

The equilibrium conditions (25) are equivalent to [cf. (23)]

$$
\begin{aligned}
0 & =\frac{\partial I_{\Pi}}{\partial w_{p}}+\frac{\partial I_{\Pi}}{\partial w_{p}^{*}} \frac{d w_{p}^{*}}{d w_{p}}-\frac{\partial I_{\Pi}}{\partial R_{\Pi}} \frac{\partial R_{\Pi}}{\partial w_{p}}=\frac{\partial \Pi}{\partial w_{p}}+\frac{\partial \Pi}{\partial w_{p}^{*}} \varphi-\frac{\partial R_{\kappa}}{\partial w_{p}}, \\
0 & =\frac{\partial I_{\Pi}}{\partial w_{s}}-\frac{\partial I_{\Pi}}{\partial R_{\Pi}} \frac{\partial R_{\Pi}}{\partial w_{s}}=\frac{\partial \Pi}{\partial w_{s}}-\frac{\partial R_{\kappa}}{\partial w_{s}}, \\
0 & =\frac{\partial I_{W}}{\partial w_{p}}+\frac{\partial I_{W}}{\partial w_{p}^{*}} \frac{d w_{p}^{*}}{d w_{p}}-\frac{\partial I_{W}}{\partial R_{W}} \frac{\partial R_{W}}{\partial w_{p}}=\frac{\partial W}{\partial w_{p}}+\frac{\partial W}{\partial w_{p}^{*}} \varphi-\frac{\partial R_{W}}{\partial w_{p}}, \\
0 & =\frac{\partial I_{W}}{\partial w_{s}}-\frac{\partial I_{W}}{\partial R_{W}} \frac{\partial R_{W}}{\partial w_{s}}=\frac{\partial W}{\partial w_{s}}-\frac{\partial R_{\kappa}}{\partial w_{s}} .
\end{aligned}
$$

Thus, in equilibrium the change in the contributions of the employer (labor) lobby, $R_{\Pi}\left(R_{W}\right)$, due to a change in a wage equals the effect of that wage on 
the welfare of that lobby, $\Pi(W)$ :

$\frac{\partial R_{\Pi}}{\partial w_{p}}=\frac{\partial \Pi}{\partial w_{p}}+\frac{\partial \Pi}{\partial w_{p}^{*}} \varphi, \frac{\partial R_{\Pi}}{\partial w_{s}}=\frac{\partial \Pi}{\partial w_{s}}, \frac{\partial R_{W}}{\partial w_{p}}=\frac{\partial W}{\partial w_{p}}+\frac{\partial W}{\partial w_{p}^{*}} \varphi, \frac{\partial R_{W}}{\partial w_{s}}=\frac{\partial W}{\partial w_{s}}$.

In other words, the contribution schedules $R_{\Pi}$ and $R_{W}$ are locally truthful. This concept can be extended to a globally truthful contribution schedule that represents the preferences of the employer (union) lobby at all policy points (cf. Berhheim and Whinston 1986 or Dixit et al. 1994). Given (27), this truthful contribution function takes the form

$$
R_{\Pi}=\max [\Pi-\underline{\Pi}, 0], \quad R_{W}=\max [W-\underline{W}, 0],
$$

where $\underline{\Pi}(\underline{W})$ is the employers (workers) rents, when the employer (union) lobby does not pay contributions but the common agency chooses its best response, given the contribution schedule of the union (employer) lobby.

Let $w_{p}$ and $w_{s}$ be the wages that would maximize the workers' rents $W$ :

$$
\left(\underline{w}_{p}, \underline{w}_{s}\right)=\arg \max _{\left(w_{s}, w_{p}\right) \text { s.t. }(24)} W .
$$

The threat points $\underline{\Pi}$ and $\underline{W}$ are then determined as follows. If the employer lobby does not pay contributions to the common agency, $R_{\Pi}=0$, then the latter retaliates by increasing the wages to the level $\left(\underline{w}_{p}, \underline{w}_{s}\right)$ set by the monopoly union. In that case, $\left.\underline{\Pi} \doteq \Pi\right|_{\left(w_{p}, w_{s}\right)=\left(\underline{w}_{p}, \underline{w}_{s}\right), R_{\Pi}=0}$. If the union lobby does not pay contributions to the agency, $R_{W}=0$, then the latter retaliates by decreasing the wages to the level of the competitive wage $w_{m}$. In that case, $\left.\underline{W} \doteq W\right|_{w_{p}=w_{s}=w_{m}, R_{W}=0}$. Thus, $\underline{\Pi}$ and $\underline{W}$ are given for the lobbies. Given this and (28), the common agency's equilibrium conditions (26) become

$$
\left(w_{s}, w_{p}\right)=\arg \max _{\left(w_{s}, w_{p}\right) \text { s.t. }(24)}\left(R_{\Pi}+R_{W}\right)=\arg \max _{\left(w_{s}, w_{p}\right) \text { s.t. }(24)}(\Pi+W) .
$$


This result can be rephrased as follows:

Proposition 1. In equilibrium, the common agency behaves as if it maximized total rents in the unionized sectors, $W+\Pi$, taking the foreign common agency's response (24) into account.

The Nash equilibrium of the lobbies in truthful strategies implements an efficient action for the lobbies taken together (cf. Dixit et al. 1997). In the model of this article, this means that if the unions and employers acted together as a group, then they would maximize their total income $W+\Pi$.

\section{General equilibrium effects}

Because the home and foreign countries are identical and one unit of each good $i$ is made of one unit of labor, then, in equilibrium, it is true that

$$
I^{*}=I, \quad w_{p}^{*}=w_{p}, \quad w_{s}^{*}=w_{s}, \quad w_{m}^{*}=w_{m}, \quad l_{s}=l_{s}^{*}, \quad l_{p}=l_{p}^{*}, \quad l_{m}=l_{m}^{*} .
$$

In that equilibrium, the common agency's equilibrium conditions (29) define aggregate income $I$ and sector-specific employment levels $l_{m}, l_{s}$ and $l_{p}$ as functions of the globalization parameters $\varphi, \tau, \alpha$ and $\beta$ (cf. Appendix B):

$$
\begin{aligned}
& I(\varphi, \tau, \alpha, \beta), \quad l_{s}(\varphi, \tau, \alpha, \beta), \quad l_{m}(\varphi, \tau, \alpha, \beta), \quad l_{p}(\varphi, \tau, \alpha, \beta) \\
& \left(\frac{\partial I}{\partial \alpha}-\frac{\partial I}{\partial \beta}\right)_{\varphi=1}=\left.\frac{\partial l_{\ell}}{\partial \tau}\right|_{\varphi=1}=\left(\frac{\partial l_{\ell}}{\partial \alpha}-\frac{\partial l_{\ell}}{\partial \beta}\right)_{\varphi=1}=0 \text { for } \ell \in\{m, s, o\} \\
& \left.I\right|_{\varphi=0}<\left.I\right|_{\varphi=1}, \quad \frac{\partial I}{\partial \tau}<0, \\
& \left.l_{m}\right|_{\varphi=0}>\left.l_{m}\right|_{\varphi=1},\left.\quad \frac{\partial l_{m}}{\partial \tau}\right|_{\varphi=0}>0, \quad\left(\frac{\partial l_{m}}{\partial \alpha}-\frac{\partial l_{m}}{\partial \beta}\right)_{\varphi=0}<0,\left.\quad l_{s}\right|_{\varphi=0}>\left.l_{s}\right|_{\varphi=1}, \\
& \left.\frac{\partial l_{s}}{\partial \tau}\right|_{\varphi=0}>0, \quad\left(\frac{\partial l_{s}}{\partial \alpha}-\frac{\partial l_{s}}{\partial \beta}\right)_{\varphi=0}<0,\left.\quad l_{p}\right|_{\varphi=0}<\left.l_{p}\right|_{\varphi=1},\left.\quad \frac{\partial l_{p}}{\partial \tau}\right|_{\varphi=0}<0 \\
& \left(\frac{\partial l_{p}}{\partial \alpha}-\frac{\partial l_{p}}{\partial \beta}\right)_{\varphi=0}>0 .
\end{aligned}
$$

The results (32) and (33) can be rephrased as follows: 
Proposition 2. A shift from national to international labor market regulation (i.e. the increase of $\varphi$ from 0 to 1 ) promotes welfare $I$. A decrease in the trade cost $\tau$ increases welfare $I$ with national $(\varphi=0)$, but neither it nor opening up shielded sectors to trade (i.e. an increase in $\alpha$ with an equal decrease in $\beta$ ) has welfare and employment effects with international labor market regulation $(\varphi=1)$.

When labor market regulation is coordinated for two identical countries, these behave as if they were a single country with no distortion from mutual trade. This makes trade policy measures ineffective.

Differentiating the employment functions $l_{m}, l_{s}$ and $l_{p}$ [cf. (9) and (14)] totally and noting (34) and $w_{p}^{*}=w_{p}[\mathrm{cf} .(30)]$ lead to the following results:

$$
\begin{aligned}
& \frac{\partial w_{m}}{\partial \varphi}>0,\left.\frac{\partial w_{m}}{\partial \tau}\right|_{\varphi=0}<0, \quad\left(\frac{\partial w_{m}}{\partial \alpha}-\frac{\partial w_{m}}{\partial \beta}\right)_{\varphi=0}>0, \frac{\partial w_{s}}{\partial \varphi}>0,\left.\frac{\partial w_{s}}{\partial \tau}\right|_{\varphi=0}<0 \\
& \left(\frac{\partial w_{s}}{\partial \alpha}-\frac{\partial w_{s}}{\partial \beta}\right)_{\varphi=0}>0, \frac{\partial w_{p}}{\partial \varphi}<0,\left(\frac{\partial w_{p}}{\partial \alpha}-\frac{\partial w_{p}}{\partial \beta}\right)_{\varphi=0}<0 .
\end{aligned}
$$

These results can be rephrased as follows:

Proposition 3. A shift from national to international labor market regulation (i.e. the increase of $\varphi$ from 0 to 1) decreases the open-sector relative wage (i.e. $w_{p}$ relative to $w_{s}$ and $w_{m}$ ). Opening up shielded sectors to trade (i.e. an increase in $\alpha$ with an equal decrease in $\beta$ ) decreases the open-sector relative wage with national $(\varphi=0)$, but has no effect on wages with international regulation $(\varphi=1)$.

Propositions 2 and 3 are in contrast to Kreickemeier and Meland (2013), who, assuming monopoly unions, prove that trade cost reductions decrease welfare. This difference can be explained as follows. In KM, a decrease in trade costs hampers welfare, because consumption levels become more unequal, reducing welfare through the concavity of the utility function. In this document, the common agency limits the bargaining power of the opensector labor unions to ensure that the welfare losses due to high open-sector wages do not outweigh the direct efficiency benefits from trade cost decreases. 


\section{Conclusions}

In this article, I examine two identical integrated countries with partially oligopolistic sectors and labor market regulation. The lobbies of unions and employers influence the common agency for revising labor market rules in their favor. In the end, this determines the wages in the oligopolistic sectors. Traditionally, globalization is examined through the general equilibrium effects of two changes: trade cost reductions and opening up shielded sectors to trade. In this article, the international coordination of labor market regulation is the third aspect of globalization. The main results are the following.

In Kreickemeier and Meland (2013), the union wages are determined by monopoly unions which are microeconomic agents taking the competitive wage as given. In that case, union wages are set as mark ups (or premiums) over and above the competitive wage so that all wages change in proportion. In this article, the level of wages is ultimately determined by the common agencies that are macroeconomic agents. Thus, the open-sector wages can change in the opposite direction than the other wages in the economy.

Because the Nash equilibrium of the union and employer lobbies in truthful strategies implements an efficient action for them taken together, the common agency maximizes the sum of the workers' and employers' rents by wages in equilibrium. If the common agencies of the two countries behave in Cournot manner, then the open-sector relative wages rise too high from the welfare point of view. That distortion is eliminated, if labor market regulation is brought to the international level.

Furthermore, Kreickemeier and Meland (2013) argue that a reduction in trade costs decreases aggregate welfare, because monopoly unions increase their rents too much over and above the competitive wage. In the model of this document, the political process of labor market regulation moderates open-sector wage increases enough to allow aggregate welfare to increase. A decrease in trade costs improve employment in the open sectors. This generates migration of workers from the "worse-paid" competitive sectors to the "better-paid" open sectors, increasing competitive wages. This will push up shielded-sector wages, so that open-sector wages will fall relative to wages paid elsewhere in the economy. When labor market regulation is coordinated for two identical countries, these behave as a single country with 
no distortion from mutual trade. In that case, trade cost reductions have no effect on employment and aggregate welfare.

The evidence on declining union power with globalization in many countries (cf. section 1) can be explained by the results of this article as follows. A decrease in trade costs and opening up shielded sectors to trade $(i)$ weaken labor unions in the open sectors, and simultaneously $(i i)$ increase the proportion and weight of open sectors in the economy.

\section{Appendix A. Wage settlement}

The microfoundations of labor market regulation are the following. On the one hand, when the labor union and the employer federation alternate in making offers to each other, they behave as if they jointly maximized a weighed geometric average of their utilities (cf. Binmore, Rubinstein and Wolinsky 1986, or Palokangas 2000, Ch. 1). The weight of such an average, which reflects the relative bargaining power of the parties, depends on labor market regulations (e.g. restrictions in starting a dispute, the intermediation of disputes). On the other hand, both the employer's and the union's reference utility in wage bargaining hinges on how many of the workers can participate in a strike. ${ }^{4}$ These things depend on labor market regulations.

Consider collective bargaining in oligopolistic sector $i \in P \cup S$ where the labor union attempts to maximize the workers' rents $v(i)$ [cf. (19)], while the employer federation attempts to maximize the employers' rent $\pi(i)$ [cf. (18)], both noting the labor demand function $l(i)$ [cf. (9) or (14)], and taking all the other wages $w_{m}, w^{*}(i)$ and $w(j)$ for $j \neq i$ as given.

The common agency prevents $\epsilon(i)$ employed workers from striking. ${ }^{5}$ Then,

\footnotetext{
${ }^{4}$ Some papers assume that the expected wage outside the firm is the union's reference point, but this is not quite in line with the microfoundations of the alternating offers game. Binmore, Rubinstein and Wolinsky (1986, pp. 177, 185-6) state that the the reference income should not be identified with the outside option point. Rather, despite the availability of these options, it remains appropriate to identify the reference income with the income streams accruing to the parties in the course of the dispute. For example, if the dispute involves a strike, these income streams are the employee's income from temporary work, union strike funds, and similar sources, while the employer's income might derive from temporary arrangements that keeps the business running.

${ }^{5}$ In many countries, there is a concept of "protection work": the number $\epsilon(i)$ of workers
} 
the unions' and employers' reference utilities under disputes, $\underline{v}(i)$ and $\underline{\pi}(i)$, are their utilities $v(i)$ and $\pi(i)$ with employment $l(i)=\epsilon(i):^{6}$

$$
\left.\underline{v}(i) \doteq v(i)\right|_{l(i)=\epsilon(i)},\left.\quad \underline{\pi}(i) \doteq \pi(i)\right|_{l(i)=\epsilon(i)} .
$$

Because the employers are willing to employ more than $\epsilon(i)$ workers, then

$$
\frac{\partial \underline{\pi}(i)}{\partial \epsilon(i)}=\left.\frac{\partial \pi(i)}{\partial l(i)}\right|_{l(i)=\epsilon(i)}>0
$$

Let $\delta(i)$ be relative union bargaining power. The outcome of wage bargaining is obtained by maximizing the Generalized Nash Product of the parties' utilities, $\Theta(i) \doteq \log [v(i)-\underline{v}(i)]+[1 / \delta(i)-1] \log [\pi(i)-\underline{\pi}(i)]$, by the wage $w(i)$, given all the other wages $w_{m}, w^{*}(i)$ and $w(j)$ for $j \neq i$. The first-order and second-order conditions of this maximization are

$$
\frac{\partial \Theta(i)}{\partial w(i)}=\frac{1}{v(i)-\underline{v}(i)} \frac{\partial v(i)}{\partial w(i)}+\frac{1 / \delta(i)-1}{\pi(i)-\underline{\pi}(i)} \frac{\partial \pi(i)}{\partial w(i)}=0, \quad \frac{\partial^{2} \Theta(i)}{\partial w(i)^{2}}<0
$$

I assume that the tariff $\tau$ is small enough to yield $\frac{\partial \pi(i)}{\partial w(i)}<0$ for $i \in P \cup S$.

Because the open and shielded sectors are identical, respectively, the common agency sets them the same relative union bargaining power, $\delta(i)=\delta_{p}$ for $i \in P$ and $\delta(i)=\delta_{s}$ for $i \in S$, and the same striking constraints, $\epsilon(i)=\epsilon_{p}$ for $i \in P$ and $\epsilon(i)=\epsilon_{s}$ for $i \in S$. Differentiating the first-order condition (A.3) and noting (A.1) and (A.2), one can see that the wage is an increasing function of relative union bargaining power $\delta(i)$ and the number $\epsilon(i)$ of protection workers in each oligopolistic home sector $i \in P \cup S$ :

$$
\frac{\partial w(i)}{\partial \delta(i)}=-\frac{\partial^{2} \Theta^{\ell}}{\partial w(i) \partial \delta(i)} / \frac{\partial^{2} \Theta^{\ell}}{\partial w(i)^{2}}=\underbrace{\frac{\delta(i)^{-2}}{\pi(i)-\pi(i)}}_{+} \underbrace{\frac{\partial \pi(i)}{\partial w(i)}}_{-} / \underbrace{\frac{\partial^{2} \Theta^{\ell}}{\partial w(i)^{2}}}_{-}>0,
$$

that is considered to be necessary to "protect" the "normal" functioning of the society. It is, of course, a political matter to judge what is normal.

${ }^{6}$ The firm is ready to employ workers over the level $\epsilon(i)$. 


$$
\frac{\partial \widetilde{w}(i)}{\partial \epsilon(i)}=-\frac{\partial^{2} \Theta^{\ell}}{\partial w(i) \partial \epsilon(i)} / \frac{\partial^{2} \Theta^{\ell}}{\partial w(i)^{2}}=\underbrace{\frac{1 / \delta(i)-1}{[\pi(i)-\underline{\pi}(i)]^{2}}}_{+} \underbrace{\frac{\partial \pi(i)}{\partial w(i)}}_{-} \underbrace{\frac{\partial \underline{\pi}(i)}{\partial \epsilon(i)}}_{+} / \underbrace{\frac{\partial^{2} \Theta^{\ell}}{\partial w(i)^{2}}}_{-}>0 .
$$

Thus, the common agency can set the wage $w(i)$ at any level by its policy variables $\delta(i)$ and $\epsilon(i)$ for $i \in P \cup S$.

\section{Appendix B. Results (31)-(34)}

From (5), (9), (14) and (17) it follows that

$$
\begin{aligned}
& l_{s}=c_{s}=\frac{a-p_{s}}{b}, \quad c_{p}=\frac{a-p_{p}}{b}, \quad \frac{d p_{s}}{d w_{s}}=\frac{n}{n+1} \\
& \frac{\partial p_{p}}{\partial w_{p}}=\frac{\partial p_{p}}{\partial w_{p}^{*}}=\frac{\partial p_{p}}{\partial \tau}=\frac{n}{2 n+1}, \quad \frac{\partial w_{m}}{\partial w_{s}}=-\frac{\beta}{\gamma} \frac{n}{n+1}, \quad \frac{\partial w_{m}}{\partial w_{p}}=-2 \frac{\alpha}{\gamma} \frac{(n+1) n}{2 n+1} \\
& \frac{\partial w_{m}}{\partial w_{p}^{*}}=2 \frac{\alpha}{\gamma} \frac{n^{2}}{2 n+1}, \quad \frac{\partial w_{m}}{\partial \tau}=-\frac{\alpha}{\gamma} \frac{n}{2 n+1},\left.\quad \frac{\partial w_{m}}{\partial \alpha}\right|_{d \beta=-d \alpha}=\frac{b}{\gamma}\left(l_{p}-l_{s}\right) . \quad \text { B.1) }
\end{aligned}
$$

Noting (21), (22) and (B.1), I define total rents:

$$
\begin{aligned}
J & \doteq W+\Pi=\alpha\left[\left(p_{p}-w_{m}\right) c_{p}+\tau \frac{n}{b}\left(w_{p}-w_{p}^{*}\right)\right]+\beta\left(p_{s}-w_{m}\right) l_{s} \\
& =\frac{\alpha}{b}\left[\left(p_{p}-w_{m}\right)\left(a-p_{p}\right)+\tau n\left(w_{p}-w_{p}^{*}\right)\right]+\frac{\beta}{b}\left(p_{s}-w_{m}\right)\left(a-p_{s}\right) \\
& =\frac{\alpha}{b}\left[\left(a+w_{m}\right) p_{p}-p_{p}^{2}-a w_{m}+\tau n\left(w_{p}-w_{p}^{*}\right)\right]+\frac{\beta}{b}\left[\left(a+w_{m}\right) p_{s}-p_{s}^{2}-a w_{m}\right] .
\end{aligned}
$$

Given (B.1), the function (B.2) has following partial derivatives:

$$
\begin{aligned}
\frac{\partial J}{\partial w_{s}} & =\frac{\beta}{b}\left(a+w_{m}-2 p_{s}\right) \frac{d p_{s}}{d w_{s}}+\left[\frac{\alpha}{b}\left(p_{p}-a\right)+\frac{\beta}{b}\left(p_{s}-a\right)\right] \frac{\partial w_{m}}{\partial w_{s}} \\
& =\beta \frac{n / \gamma}{n+1}\left[\gamma\left(2 l_{s}-l_{m}\right)+\alpha c_{p}+\beta l_{s}\right] \\
\frac{\partial J}{\partial w_{p}} & =\frac{\alpha}{b}\left[\left(a+w_{m}-2 p_{p}\right) \frac{\partial p_{p}}{\partial w_{p}}+\tau n\right]+\left[\frac{\alpha}{b}\left(p_{p}-a\right)+\frac{\beta}{b}\left(p_{s}-a\right)\right] \frac{\partial w_{m}}{\partial w_{p}}
\end{aligned}
$$




$$
\begin{aligned}
& =\frac{\alpha}{\gamma} \frac{n}{2 n+1}\left[\gamma\left(2 c_{p}-l_{m}\right)+(2 n+1) \frac{\gamma}{b} \tau+2(n+1)\left(\alpha c_{p}+\beta l_{s}\right)\right] \\
\frac{\partial J}{\partial w_{p}^{*}} & =\frac{\alpha}{b}\left[\left(a+w_{m}-2 p_{p}\right) \frac{\partial p_{p}}{\partial w_{p}^{*}}-\tau n\right]+\left[\frac{\alpha}{b}\left(p_{p}-a\right)+\frac{\beta}{b}\left(p_{s}-a\right)\right] \frac{\partial w_{m}}{\partial w_{p}^{*}} \\
& =\frac{\alpha}{\gamma} \frac{n}{2 n+1}\left[\gamma\left(2 c_{p}-l_{m}\right)-(2 n+1) \frac{\gamma}{b} \tau-n\left(\alpha c_{p}+\beta l_{s}\right)\right] \\
\frac{\partial J}{\partial w_{p}} & +\varphi \frac{\partial J}{\partial w_{p}^{*}}=\frac{\alpha}{\gamma} \frac{n}{2 n+1}\left\{(1+\varphi) \gamma\left(2 c_{p}-l_{m}\right)+(1-\varphi)(2 n+1) \frac{\gamma}{b} \tau\right. \\
\frac{\partial J}{\partial \tau}= & \frac{\alpha}{b}\left(a+w_{m}-2 p_{p}\right) \frac{\partial p_{p}}{\partial \tau}+\left[\frac{\alpha}{b}\left(p_{p}-a\right)+\frac{\beta}{b}\left(p_{s}-a\right)\right] \frac{\partial w_{m}}{\partial \tau} \\
= & \frac{\alpha}{\gamma} \frac{n}{2 n+1}\left[\gamma\left(2 c_{p}-l_{m}\right)+\alpha c_{p}+\beta l_{m}\right] \\
\left.\frac{\partial J}{\partial \alpha}\right|_{d \beta=-d \alpha} & =\left(p_{p}-w_{m}\right) c_{p}+\tau \frac{n}{b}\left(w_{p}-w_{p}^{*}\right)-\left(p_{s}-w_{m}\right) l_{s} \\
= & \left(l_{m}-l_{p}\right) b c_{p}+\tau \frac{n}{b}\left(w_{p}-w_{p}^{*}\right)-\left(l_{m}-l_{s}\right) b l_{s}-\left(\alpha c_{p}+\beta l_{s}\right) \frac{b}{\gamma}\left(l_{p}-l_{s}\right)
\end{aligned}
$$

Given (27) and (B.2), the first-order conditions for maximization (26) are

$$
\begin{aligned}
0 & =\frac{\partial\left(R_{\Pi}+R_{W}\right)}{\partial w_{s}}=\frac{\partial(\Pi+W)}{\partial w_{s}}=\frac{\partial J}{\partial w_{s}} \\
0 & =\frac{\partial\left(R_{\Pi}+R_{W}\right)}{\partial w_{p}}=\frac{\partial R_{\Pi}}{\partial w_{p}}+\frac{\partial R_{W}}{\partial w_{p}}=\frac{\partial \Pi}{\partial w_{p}}+\varphi \frac{\partial \Pi}{\partial w_{p}^{*}}+\frac{\partial W}{\partial w_{p}}+\varphi \frac{\partial W}{\partial w_{p}^{*}} \\
& =\frac{\partial(\Pi+W)}{\partial w_{p}}+\frac{\partial(\Pi+W)}{\partial w_{p}^{*}} \varphi=\frac{\partial J}{\partial w_{p}}+\varphi \frac{\partial J}{\partial w_{p}^{*}}
\end{aligned}
$$

I assume that the second-order condition holds for $\varphi \in\{0,1\}$.

Because the countries are identical, $w_{p}^{*}=w_{p}$ and $c_{p}=l_{p}$ hold true in equilibrium [cf. (30)]. Inserting these, (B.3) and (B.5) into the first-order conditions (B.8) and (B.9), I obtain the equations

$0=\alpha l_{p}+\beta l_{s}+\gamma\left(2 l_{s}-l_{m}\right)$ 
$0=2[(1-\varphi) n+1]\left(\alpha l_{p}+\beta l_{s}\right)+(1+\varphi) \gamma\left(2 l_{p}-l_{m}\right)+(1-\varphi)(2 n+1) \gamma \tau / b$.

From (B.10), (B.11) and $0 \leq \varphi \leq 1$ it follows that

$$
\begin{gathered}
l_{s}-l_{m} / 2=-\left(\alpha l_{p}+\beta l_{s}\right) / 2<0 \\
l_{p}-l_{s}=\frac{l_{m}}{2}-l_{s}-\frac{(1-\varphi) n+1}{(1+\varphi) \gamma}\left(\alpha l_{p}+\beta l_{s}\right)-(1-\varphi)\left(n+\frac{1}{2}\right) \frac{\tau}{b} \\
=\left[\frac{1}{2}-\frac{(1-\varphi) n+1}{(1+\varphi) \gamma}\right]\left(\alpha l_{p}+\beta l_{s}\right)-(1-\varphi)\left(n+\frac{1}{2}\right) \frac{\tau}{b} \\
\left(l_{p}-l_{s}\right)_{\varphi<1}=[\frac{1}{2}-\underbrace{\frac{(1-\varphi) n+1}{(1+\varphi) \gamma}}_{>\frac{1}{2}}](\underbrace{\alpha l_{p}+\beta l_{s}}_{+})-(\underbrace{1-\varphi}_{>0}) \underbrace{\left(n+\frac{1}{2}\right) \frac{\tau}{b}}_{+}<0 \\
\left(l_{p}-l_{s}\right)_{\varphi=1}=0, \\
l_{p} \leq l_{s}<\frac{l_{m}}{2}, \quad L=\int_{0}^{1} l(i) d i>\min _{i \in[0,1]} l(i)=l_{p} .
\end{gathered}
$$

Noting (B.6), (B.9), (B.10), (B.13), $w_{p}^{*}=w_{p}$ and $c_{p}=l_{p}[\mathrm{cf.}$ (30)], I obtain

$$
\begin{aligned}
& \frac{\partial J}{\partial \tau}=\frac{\alpha}{\gamma} \frac{n}{2 n+1}\left[\gamma\left(2 l_{p}-l_{m}\right)+\alpha c_{p}+\beta l_{m}\right], \\
& \frac{\partial J}{\partial \alpha}=\left(l_{m}-l_{p}\right) b l_{p}-\left(l_{m}-l_{s}\right) b l_{s}-\left(\alpha l_{p}+\beta l_{s}\right) \frac{b}{\gamma}\left(l_{p}-l_{s}\right), \\
& \frac{\partial J}{\partial w_{p}}+\frac{\partial J}{\partial w_{p}^{*}}=(1-\varphi) \frac{\partial J}{\partial w_{p}^{*}} \\
& =\frac{\alpha}{\gamma} \frac{n}{2 n+1}(1-\varphi)\left[\gamma\left(2 c_{p}-l_{m}\right)-(2 n+1) \frac{\gamma}{b} \tau-n\left(\alpha c_{p}+\beta l_{s}\right)\right] .
\end{aligned}
$$

Noting $w_{p}^{*}=w_{p},($ B.2) and (B.8), the determination of income, (20), and the full-employment constraint (16) take the form:

$$
\begin{aligned}
& 0=\alpha\left(a-b l_{p}\right) l_{p}+\beta\left(a-b l_{s}\right) l_{s}+\gamma\left(a-b l_{m}\right) l_{m}-I, \\
& 0=\alpha l_{p}+\beta l_{s}+\gamma l_{m}-L .
\end{aligned}
$$


The system of four equations, (B.17), (B.18), (B.10) and (B.11), has four unknown variables - income $I$ and employment levels $l_{m}, l_{s}$ and $l_{p}-$ and four parameters $\varphi, \tau, \alpha$ and $\beta$. Differentiating this system totally yields

$$
\begin{aligned}
& {\left[\begin{array}{cccc}
-1 & \gamma\left(a-2 b l_{m}\right) & \beta\left(a-2 b l_{s}\right) & \alpha\left(a-2 b l_{p}\right) \\
0 & \gamma & \beta & \alpha \\
0 & -\gamma & \beta+2 \gamma & \alpha \\
0 & -(1+\varphi) \gamma & 2 \beta[(1-\varphi) n+1] & \begin{array}{c}
2 \alpha[(1-\varphi) n+1] \\
+2(1+\varphi) \gamma
\end{array}
\end{array}\right]\left[\begin{array}{c}
d I \\
d l_{m} \\
d l_{s} \\
d l_{p}
\end{array}\right]} \\
& +\left[\begin{array}{ccc}
0 & 0 & {\left[a-b\left(l_{p}+l_{s}\right)\right]} \\
0 & 0 & l_{p}-l_{s} \\
0 & 0 & l_{p}-l_{s} \\
\vartheta & (1-\varphi)(2 n+1) \frac{\gamma}{b} & \begin{array}{c}
2[(1-\varphi) n+1] \\
\left(l_{p}-l_{s}\right)
\end{array}
\end{array}\right]\left[\begin{array}{c}
d \varphi \\
d \tau \\
d \alpha-d \beta
\end{array}\right]=0,
\end{aligned}
$$

where, by (B.13), it holds true that

$$
\vartheta \doteq \gamma(\underbrace{2 l_{p}-l_{m}}_{-})-\underbrace{2 \varphi\left(\alpha l_{p}+\beta l_{s}\right)}_{+}-\underbrace{(2 n+1) \frac{\gamma}{b} \tau}_{+}<0 .
$$

The Jacobian of this system is

$$
K=-2 \gamma^{2}\{2 \alpha[(1-\varphi) n+1]+2(1+\varphi) \gamma+(2 \beta+\alpha)(1+\varphi)\}<0 .
$$

Noting (B.12) and (B.13), the matrix equation (B.19) can be written in terms of partial derivatives:

$$
\frac{\partial I}{\partial \varphi}=\underbrace{\frac{4}{K}}_{-} b \underbrace{\vartheta}_{-} \alpha \gamma\left[\gamma(\underbrace{l_{m}-l_{p}}_{+})+\beta(\underbrace{l_{s}-l_{p}}_{\geq 0})\right]>0,
$$




$$
\begin{aligned}
& \frac{\partial I}{\partial \tau}=\underbrace{\frac{4}{K}}_{-} b \underbrace{(1-\varphi)(2 n+1) \frac{\gamma}{b}}_{+} \alpha \gamma\left[\gamma(\underbrace{l_{m}-l_{p}}_{+})+\beta(\underbrace{l_{s}-l_{p}}_{\geq 0})\right]\left\{\begin{array}{l}
=0 \Leftrightarrow \varphi=1, \\
<0 \Leftrightarrow \varphi<1,
\end{array}\right. \\
& \frac{\partial I}{\partial \alpha}-\frac{\partial I}{\partial \beta}=2 \frac{\gamma^{2}}{K}\left(l_{p}-l_{s}\right) b\left\{(1+\varphi)\left[\gamma\left(l_{p}+l_{s}-2 l_{m}\right)+2 \beta\left(l_{p}-l_{s}\right)\right]\right. \\
& \left.+\alpha\left(l_{s}-l_{p}\right)\left[(1-\varphi) n+1+(1+\varphi)\left(\frac{1}{2}+\frac{\beta}{\alpha}\right)\right]\right\} \\
& =0 \Leftrightarrow l_{p}=l_{s} \Leftrightarrow \varphi=1 \text {, } \\
& \frac{\partial l_{m}}{\partial \varphi}=-2 \gamma \alpha \underbrace{\frac{1}{K}}_{-} \underbrace{\vartheta}_{-}<0 \\
& \frac{\partial l_{m}}{\partial \tau}=-2 \gamma \alpha \underbrace{\frac{1}{K}}_{-} \underbrace{(2 n+1) \frac{\gamma}{b}}_{+}(1-\varphi) \begin{cases}=0 & \Leftrightarrow \varphi=1, \\
>0 & \Leftrightarrow \varphi<1,\end{cases} \\
& \frac{\partial l_{m}}{\partial \alpha}-\frac{\partial l_{m}}{\partial \beta}=\underbrace{4 \gamma^{2}(1+\varphi)}_{+}\left(l_{p}-l_{s}\right) \underbrace{\frac{1}{K}}_{-}\left\{\begin{array}{cc}
=0 & \Leftrightarrow l_{0}=l_{s} \Leftrightarrow \varphi=1, \\
>0 & \Leftrightarrow l_{0}<l_{s} \Leftrightarrow \varphi<1,
\end{array}\right. \\
& \frac{\partial l_{s}}{\partial \varphi}=-2 \gamma \alpha \underbrace{\frac{1}{K}}_{-} \underbrace{\vartheta}_{-\vartheta}<0 \\
& \frac{\partial l_{s}}{\partial \tau}=-2 \gamma \alpha \underbrace{\frac{1}{K}}_{-} \underbrace{(2 n+1) \frac{\gamma}{b}}_{+}(1-\varphi) \begin{cases}=0 & \Leftrightarrow \varphi=1, \\
>0 & \Leftrightarrow \varphi<1,\end{cases} \\
& \frac{\partial l_{s}}{\partial \alpha}-\frac{\partial l_{s}}{\partial \beta}=4 \gamma \underbrace{\frac{1}{K}}\left(l_{p}-l_{s}\right)(1+\varphi) \gamma \begin{cases}=0 & \Leftrightarrow l_{0}=l_{s} \Leftrightarrow \varphi=1, \\
>0 & \Leftrightarrow l_{0}<l_{s} \Leftrightarrow \varphi<1,\end{cases} \\
& \frac{\partial l_{p}}{\partial \varphi}=\underbrace{\frac{\gamma}{K}}_{-} \underbrace{\vartheta}_{-}(2 \gamma+\beta)>0 \\
& \frac{\partial l_{p}}{\partial \tau}=2 \underbrace{\frac{\gamma}{K}}_{-} \underbrace{(2 n+1) \frac{\gamma}{b}}_{+}(\gamma+\beta)(1-\varphi)\left\{\begin{aligned}
=0 & \Leftrightarrow \varphi=1, \\
<0 & \Leftrightarrow \varphi<1,
\end{aligned}\right.
\end{aligned}
$$


$\frac{\partial l_{p}}{\partial \alpha}-\frac{\partial l_{p}}{\partial \beta}=2 \underbrace{\frac{\gamma}{K}}_{-}(\underbrace{l_{p}-l_{s}}_{-})\{\underbrace{2 \gamma[(1-\varphi) n+1]+1+\varphi}_{+}\}\left\{\begin{array}{cl}=0 & \Leftrightarrow \varphi=1, \\ >0 & \Leftrightarrow \varphi<1 .\end{array}\right.$

Because (B.22)-(B.25) hold for $\varphi \in[0,1]$, then $\left.I\right|_{\varphi=0}<\left.I\right|_{\varphi=1},\left.l_{m}\right|_{\varphi=0}>\left.l_{m}\right|_{\varphi=1}$, $\left.l_{s}\right|_{\varphi=0}>\left.l_{s}\right|_{\varphi=1}$ and $\left.l_{p}\right|_{\varphi=0}<\left.l_{p}\right|_{\varphi=1}$ hold true by the mean value theorem.

\section{Acknowledgements}

The author thanks IIASA (Laxenburg, Austria) for hospitality in Summer 2015 when the preliminary version of this paper was written, and Wolfgang Lechthaler (Kiel Institute for the World Economy, Germany) for his detailed comment on that version in DEGIT XX (Geneva, Switzerland, 2015).

\section{References:}

Acemoglu, D., Aghion, P. and Violante, G.L. (2001). Deunionzation, technical change and inequality. CEPR Discussion Paper Series No. 2764.

Abraham F., Konings J. and Vanormelingen, S. (2009). The effects of globalization on union bargaining and price-cost margins of firms. Review of World Economics, 145, pp. 13-36.

Bastos P. and Kreickemeier U., (2009). Unions, competition and trade in general equilibrium. Journal of International Economics, 79: 238-247.

Bernheim, D. and Whinston, MD., (1986). Menu auctions, resource allocation, and economic influence. Quarterly Journal of Economics, 101: 1-31.

Binmore, K., Rubinstein, A. and Wolinsky, A. (1986). The Nash bargaining solution in economic modelling. Rand Journal of Economics, 17: 176-188.

Boulhol, O., Dobbelaere, S. and Maioli S. (2011). Imports as product and labor market discipline. British Journal of Industrial Relations, 49: 311-361. Brander, J. and Krugman, PR. (1983). A 'reciprocal dumping' model of international trade. Journal of International Economics, 24: 313-321.

Dixit, A. (1986) Comparative statics for oligopoly. International Economic Review, 27(1): 107-122.

Dixit, A., Grossman, G.M. and Helpman, E. (1997). Common agency and coordination: general theory and application to management policy making. Journal of Political Economy, 105(4): 752-769. 
Driffill J. and Van der Ploeg F. (1995). Trade liberalization with imperfect competition in goods and labor markets. Scandinavian Journal of Economics, 97(2): 223-243.

Dumont, M., Rayp, G. and Willeme, P. (2006). Does internationalization affect union bargaining power? An empirical study for five EU countries. Oxford Economic papers, 58: 77-102.

Dumont, M., Rayp, G. and Willeme, P. (2012). The bargaining position of low-skilled and high-skilled workers in a globalizing world. Labor Economics, 19: 312-319.

Huizinga H. (1993). International market integration and union wage bargaining. Scandinavian Journal of Economics, 95: 249-255.

Johal, S. and Ulph, A. (2002). Globalization, lobbying, and international environmental governance. Review of International Economics, 10: 387-403.

Kreickemeier, U. and Meland, F. (2013). Non-traded goods, globalization and union influence. Economica, 80: 774-792.

Naylor R. (1998). International trade and economic integration when labor markets are generally unionized. European Economic Review, 42: 1251-1267. Naylor R. (1999). Union Wage Strategies and International Trade. Economic Journal, 109: 102-125.

Neary P. (2009). International Trade in General Oligopolistic Equilibrium', mimeo (http://users.ox.ac.uk/ econ0211/papers/pdf/gole.pdf).

Nickell, S., Nunziata, L. and Ochel, W. (2005). Unemployment in the OECD since the 1960s. What do we know? Economic Journal, 115: 127.

Palokangas, T. (2000). Labour Unions, Public Policy and Economic Growth. Cambridge (UK): Cambridge University Press.

Palokangas, T. (2003). The political economy of collective bargaining. Labor Economics, 10: 253-264.

Palokangas, T. (2014). The political economy of labor market regulation with R\&D. IZA Discussion Paper No. 8147.

Potrafke, N. (2010). Labor market deregulation and globalization: empirical evidence from OECD countries. Review of World Economics, 146: 545-571.

Saint-Paul, G. (2002a). Employment protection, international specialization, and innovation. European Economic Review, 46: 375-395.

Saint-Paul, G. (2002b). The political economy of employment protection. Journal of Political Economy, 110: 672-704. 